\title{
Non-surgical endodontic treatment of maxillary first molar with large size and curved canal: a case report
}

\author{
Adnan Habib *, Mazen Doumani, Muteb Almutairi \\ Department of Restorative Dental Sciences, Al-Farabi Colleges for Dentistry and Nursing, Riyadh, Saudi Arabia \\ *Corresponding author E-mail: adnanhabib71@hotmail.com
}

\begin{abstract}
The teeth are subjected to considerable variation for the number, size, form and structure of dental tissues. In this rare case report, a 30year-old male patient was referred for root canal treatment of his right maxillary first molar because of deep caries in this tooth. During radiographic examination for determining the working length of this tooth, the peri-apical radiographs revealed the unfamiliar size of the maxillary first molar, in addition to severe curvature in mesiobuccal root. To achieve a successful treatment instrumentation of the canals completed with a crown-down technique, and obturation was done with lateral condensation technique.
\end{abstract}

Keywords: Anomalies; Curvature; Macrodontia; Maxillary First Molar

\section{Introduction}

Knowledge of the dental anatomy and morphology is a foremost point for planning and performing endodontic therapy. There are several anatomical variations existing within the root canal system may cause failure of root canal therapy. The root canal anatomy of teeth has certain common characteristics and numerous atypical ones, which can indicate the actions necessary for successful endodontics(Slowey RR 1979). Among all teeth undergoing root canal treatment; maxillary first molars owing to their complex root and canal morphology are often known to present with a high incidence of failures, mostly relating to non identification of the (mb2)second mesiobuccal canal(Sharma S et al. 2015).

This tooth has three roots. The palatal root is the longest, with an average length of $22 \mathrm{~mm}$; the mesiobuccal and distobuccal roots are slightly shorter, at $21 \mathrm{~mm}$ average length. The percentage of mesiobuccal roots having two canals reported throughout the literature has increased steadily as research techniques have developed (Carrotte $\mathrm{P}$ 2014).

According to (Pecora J et al. 1991) the average overall length in maxillary first molarwas $21.3 \pm 1.6 \mathrm{~mm}, 20.1 \pm 1.6 \mathrm{~mm}$. $\pm 1.6 \mathrm{~mm}$. $19.6 \pm 1.5 \mathrm{~mm}$ respectively for palatal root, mesiobuccal root, and distobuccal root. (Naseri M et al. 2015) It reported that the mean tooth length of maxillary first molar was 19.3 and $20.3 \mathrm{~mm}$ in Iranian female and male patients, respectively.

Larger sizes of maxillary first molar were observed in Alam' study of tooth length and working length of first permanent molar in Bangladeshi people,this study revealed that average length of upper 1 st molar is $20.62 \mathrm{~mm}$ and for lower $1 \mathrm{st}$, molar is $20.28 \mathrm{~mm}$; the range of length for upper $1 \mathrm{st}$ molar is $17.16 \mathrm{~mm}-25.33 \mathrm{~mm}$ and for lower 16mm - 24mm (Alam M et al. 2004).

The morphology of the curved root canal is important to the outcome of root canal treatment. It is well known that when curvatures are present, endodontic preparation becomes more difficult, and there is a tendency for all preparation techniques to divert the prepared canal away from the original axis (Javaberi HH and Javaberi HG 2007).

This paper reports the case of a maxillary right first molar with large size and severe curved canal, root canal treatment and case management are described.

\section{Case report}

A 30-year old Syrian male patient was referred to the restorative dental science department in Al-Farabi colleges (Riyadh, KSA)because of the chief complaint of pain in the right maxillary posterior region for past several days ; the pain was severe , sharp, intermittent, and stimulated by cold. The patient had no history of systemic diseases or any syndrome.

Clinical and radiographic examinations (Fig.1:A) revealed distal and deep mesial caries in the maxillary first right molar. Vitality tests were performed, and the patient was diagnosed with irreversible pulpitis.

After administration of local anesthesia, tooth was isolated with a rubber dam and a conventional endodontic access opening was made. After removing pulp tissue located in the chamber, three orifices were observed palatal, mesiobuccal and distobuccal, then using DG-16 endodontic probe (Hu- Friedy, Chicago) and ultrasonic tips(Start-X ultrasonic tips, Dentsply Maillefer, Ballaigues, Switzerland) the fourth canal (Mb2) was discovered, the orifice was very small and very closed to the orifice of mesiobuccal canal. Working length of each canal was estimated by means of an electronic apex locator (Root ZX; Morita, Tokyo, Japan) and then confirmed by a radiograph , the working length of each canal was unfamiliar, it was $28 \mathrm{~mm}, 30.5 \mathrm{~mm}, 20 \mathrm{~mm}, 28 \mathrm{~mm}$ for palatal canal ,mesiobuccal canal ,second mesiobuccal canal $(\mathrm{mb} 2)$ and distobuccal canal respectively (Fig.1:B). And then access cavity was closed with a temporary restoration

The radiograph shown too severe curvature in mesiobuccal root ( $35^{\circ}$ according to Schnieder technique).

At the next visit, the canals were initially instrumented with \#15 stainless steel files (Dentsply Maillefer, Simfra, Switzerland)) 
under irrigation with $5.25 \%$ sodium hypochlorite and $17 \%$ EDTA. Coronal flaring was carried out by using $\mathrm{N}^{\circ} 25-0.12$ Endoflare $^{\circledR}$ file (Micro-mega, Besancon, France). Cleaning and shaping of the canals was done by using manual $31 \mathrm{~mm}$ length stainless steel $\mathrm{K}$ file with a crown-down technique till size 35 apically and 70 coronally except for the curved mesiobuccal canal was enlarged till 30 apically and 60 coronally .The canals were obturated with AH plus resin sealer (Dentsply Maillefer, Ballaigues, Switzerland) and gutta-percha points (Diadent Group, Chongju,Korea) using lateral condensation technique(Fig.1:C). The access cavity was then restored with posterior composite filling (Fig.2: A) (Filtek Z250, 3MESPE, St Paul, MN, USA). Digital panoramic radiograph taken after the endodontic treatment shown the large sizes of maxillary and mandibular teeth (Fig.2: B).
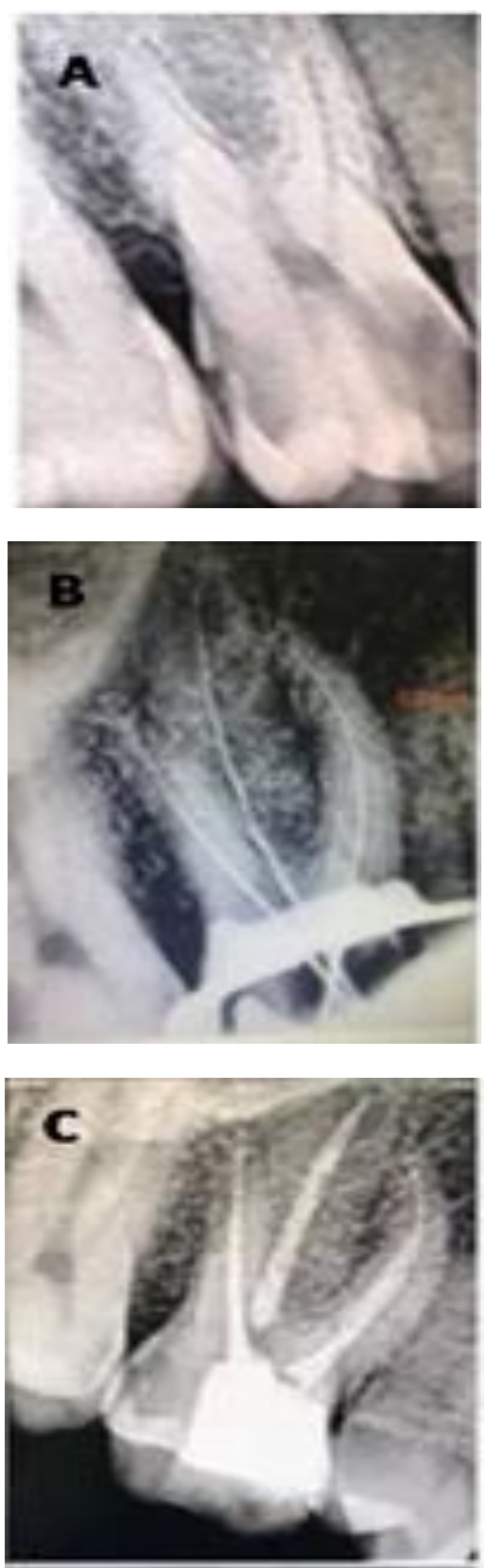

Fig. 1:View of a treated molar; (a)Preoperative radiograph showing dista and deep mesial caries in the maxillary first right molar. (B) Peri-apical radiograph for WL determination. (C) Peri-apical radiograph for obturation of four root canals in the maxillary first molar.
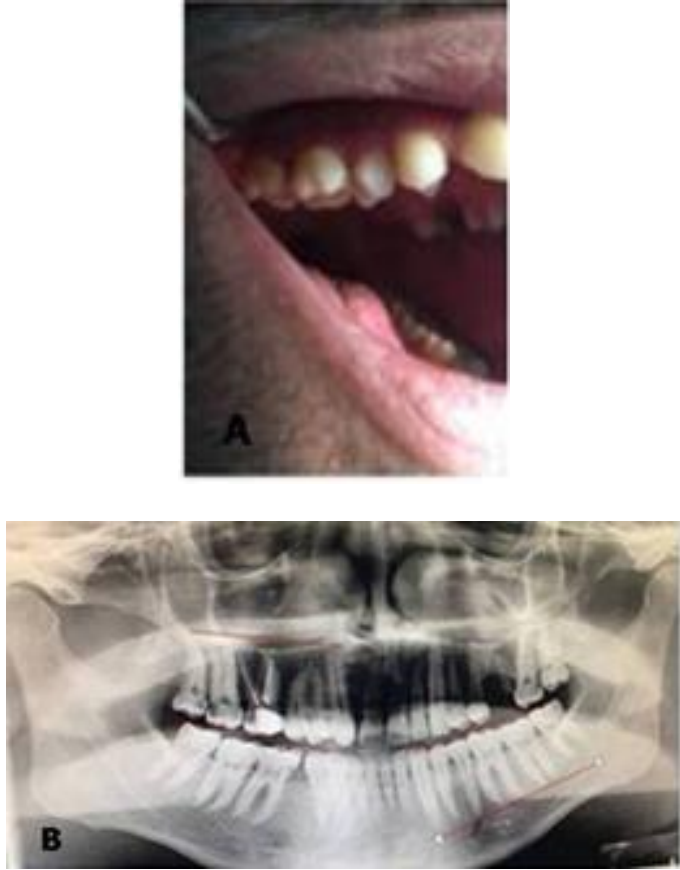

Fig. 2: (A) Large maxillary first molar after endodontic treatment and restoration. (B) Digital panoramic radiograph showing the large sizes of maxillary and mandibular teeth.

\section{Discussion}

Accurate working length determination helps to decide the extent to which the instruments are placed and worked in the root canal and will also limit the depth to which the canal filling may be placed(Seltzer S et al. 1973). The lengths of the endodontic instruments are designed to be based upon the length of the tooth. Three standard lengths are available as $21 \mathrm{~mm}, 25 \mathrm{~mm}$, and $31 \mathrm{~mm}$, these lengths usually meet the majority of endodontic cases.The studies showed that there are differences in root canal lengths among populations. It has been found that the tooth lengths in Asians were shorter than Caucasians(Kim E et al. 2005), and there was the difference in root canal lengths between Asians and western population with the latter having longer teeth (Kim J et al. 2010). Variation in size, form and morphology of the teeth resulted in anomalies such as macrodontia, microdontia, hyperdontia, hypodontia, taurodontism and dens in dente. Macrodontia or megadontia refers to teeth that appear larger than the normal size. Some or all teeth may be affected. Macrodontia can be classified as three types: true generalized macrodontia, relative generalized macrodontia and macrodontia involving a single tooth (Neville BW et al. 2007).

1) True generalized macrodontia : several teeth are larger than normal. Seen in pituitary gigantism and pineal hyperplasia with gigantism.

2) Relative generalized macrodontia : teeth are normal or slightly larger than normal in small jaws.

3) Macrodontia of single teeth : this is relatively uncommon. The tooth may appear normal in every aspect except for its size.

The etiology of macrodontia is unknown, but genetic and environmental causes have been proposed (Neville BW et al. 2007). The clinical and radiographical foundings in this case verified that the patient has true generalized macrodontia without syndromic association.

Preparation of curved canals presents one of the greatest challenges in endodontics and is fraught with difficulties. In dilacerated teeth , it is often difficult to explore and negotiate the root canals. This inability to continuously follow the root canal curvature might result in blocking of the canal, ledging, apical cavitation such as transportation and/or zipping, perforation, and instrument separation (Jain N and Tushar S 2008).

It was suggested to preflare the coronal third of the canal (at the expense of the tooth structure) to reduce the angle of curvature. 
Once this procedure is completed, it is easy to negotiate the remainder of the root canal (Guttman JL 1979).

Enlargement of the canals in this case was done by using manual stainless steel K-file with a crown-down technique, This technique is particularly useful in fine curved canals of maxillary and mandibular molars.

\section{Conclusion}

1) Macrodontia or large tooth is an uncommon anomaly; though generalized macrodontia is usually associated with syndromes this abnormality may be not associated with any syndrome.

2) Sound knowledge about anatomy of the tooth, appropriate instruments, and techniques will help manage root canals whatever its form, size, and configuration, prevent complications and enhance the quality of the treatment.

\section{Conflicts of interest}

There are no conflicts of interest

\section{Acknowledgment}

The authors acknowledge the staff of dental college in AlFarabi colleges (Riyadh KSA).

\section{References}

[1] Slowey RR (1979) Root canal anatomy. Road map to successful endodontics. Dental Clinics of North America 2(4)3:555-73.

[2] Sharma S, Mittal M, Passi D, Grover S (2015) Management of a maxillary first molar having atypical anatomy of two roots diagnosed using cone beam computed tomography. Journal of Conservative Dentistry 18(4):342-345.https://doi.org/10.4103/0972-0707.159756.

[3] Carrotte P (2004) Endodontics: Part 4 Morphology of the root canal system. British Dental Journal 197(7):379 383.https://doi.org/10.1038/sj.bdj.4811711.

[4] Pecora JD, Woelfel BJ, Sousa Neto MD(1991) Morphologic study of the maxillary molars, Part I: External anatomy .Brazilian Dental Journal 2(1):45-50.

[5] Naseri M, Safi Y, Baghban AA, Khayat A, Eftekhar L(2016) Survey of Anatomy and Root Canal Morphology of Maxillary First Molars Regarding Age and Gender in an Iranian Population Using ConeBeam Computed Tomography. Iranian Endodontic Journal 11(4):298-303

[6] Alam MS, Aziz-us-salam, Prajapati K, Rai P, Molla AA(2004) Study of tooth length and working length of first permanent molar in Bangladeshi people. Bangladesh Medical Research Council 30(1):36-42.

[7] Javaberi HH, Javaberi HG (2007) A comparison of three Ni-Ti rotary instruments in apical transportation. Journal of Endodontics33(3):284-6.https://doi.org/10.1016/j.joen.2006.05.004.

[8] Seltzer S, Saltunoff W, Smith J(1973) Biological aspects of endodontics- Periapical tissue reaction to root canal instrumentation beyond the apex and root canal filling short of and beyond the apex. Oral Surgery, Oral Medicine, Oral Pathology, Oral Radiology, and Endodontology36(5):725-730.https://doi.org/10.1016/00304220(73)90146-1.

[9] Kim E, Fallahrastegar A, Hur YY, Jung IY, Kim S, Lee SJ(2005) Difference in root canal length between Asians and Caucasians. International Endodontic Journal 38(3):149 151.https://doi.org/10.1111/j.1365-2591.2004.00881.x.

[10] Kim J, Lee S, Lee G, Park S(2010) Study of endodontic working length of Korean posterior teeth. Journal of Korean Academy of Con-

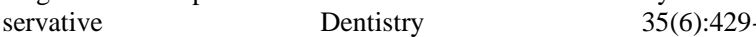
435.https://doi.org/10.5395/JKACD.2010.35.6.429.

[11] Neville BW, Damm DD, Allen AM, Bouquot JE. Oral and Maxillofacial Pathology, WB saunders Company: Philadelphia; 2007. P. 83.

[12] Jain N, Tushar S (2008) Curved canals: ancestral files revisited. Indian Journal of Dental Research 19(3):267-71. https://doi.org/10.4103/0970-9290.42964.

[13] Guttman JL. Problem solving in endodontics. 3rd ed. Missouri Mosby - Year book Inc; 1997.p. 116 